\title{
Analysis of differentially expressed Sclerotinia sclerotiorum genes during the interaction with moderately resistant and highly susceptible chickpea lines
}

Virginia W. Mwape ${ }^{1,2^{*}}$, Fredrick M. Mobegi ${ }^{1}$, Roshan Regmi ${ }^{1,2}$, Toby E. Newman ${ }^{1}$, Lars G. Kamphuis ${ }^{1,2^{*}}$ and Mark C. Derbyshire ${ }^{1}$

\begin{abstract}
Background: Sclerotinia sclerotiorum, the cause of Sclerotinia stem rot (SSR), is a host generalist necrotrophic fungus that can cause major yield losses in chickpea (Cicer arietinum) production. This study used RNA sequencing to conduct a time course transcriptional analysis of S. sclerotiorum gene expression during chickpea infection. It explores pathogenicity and developmental factors employed by S. sclerotiorum during interaction with chickpea.
\end{abstract}

Results: During infection of moderately resistant (PBA HatTrick) and highly susceptible chickpea (Kyabra) lines, 9491 and 10,487 S. sclerotiorum genes, respectively, were significantly differentially expressed relative to in vitro. Analysis of the upregulated genes revealed enrichment of Gene Ontology biological processes, such as oxidation-reduction process, metabolic process, carbohydrate metabolic process, response to stimulus, and signal transduction. Several gene functional categories were upregulated in planta, including carbohydrate-active enzymes, secondary metabolite biosynthesis clusters, transcription factors and candidate secreted effectors. Differences in expression of four S. sclerotiorum genes on varieties with different levels of susceptibility were also observed.

Conclusion: These findings provide a framework for a better understanding of S. sclerotiorum interactions with hosts of varying susceptibility levels. Here, we report for the first time on the S. sclerotiorum transcriptome during chickpea infection, which could be important for further studies on this pathogen's molecular biology.

Keywords: Sclerotinia sclerotiorum, Cicer arietinum, CAZymes, Secondary metabolites, Secreted effectors, Transcription factors, Infection

\section{Background}

Sclerotinia sclerotiorum is a necrotrophic fungal pathogen with a remarkably broad host range of over 600 plant species [1, 2]. The hosts of S. sclerotiorum include economically important crops such as Brassica napus (canola), Glycine max (soybean), Phaseolus vulgaris

\footnotetext{
* Correspondence: virginia.wainaina@postgrad.curtin.edu.au; lars.kamphuis@curtin.edu.au

${ }^{1}$ Centre for Crop and Disease Management, Curtin University, Bentley, WA 6102, Australia

Full list of author information is available at the end of the article
}

(common beans), Pisum sativum (field pea), Helianthus annuus (sunflower) and Cicer arietinum (chickpea) [1]. Research on genetic and molecular management of various fungal pathogens in chickpeas, such as Aschochyta rabiei and Fusarium oxysporum f. sp. ciceris, has led to the identification of genetic and pathological variabilities leading to shifting from cultural practices to the development of new genetic and molecular management approaches [3]. However, limited information is available on the molecular biology of $S$. sclerotiorum during

(c) The Author(s). 2021 Open Access This article is licensed under a Creative Commons Attribution 4.0 International License, which permits use, sharing, adaptation, distribution and reproduction in any medium or format, as long as you give appropriate credit to the original author(s) and the source, provide a link to the Creative Commons licence, and indicate if changes were made. The images or other third party material in this article are included in the article's Creative Commons licence, unless indicated otherwise in a credit line to the material. If material is not included in the article's Creative Commons licence and your intended use is not permitted by statutory regulation or exceeds the permitted use, you will need to obtain permission directly from the copyright holder. To view a copy of this licence, visit http://creativecommons.org/licenses/by/4.0/. The Creative Commons Public Domain Dedication waiver (http://creativecommons.org/publicdomain/zero/1.0/) applies to the data made available in this article, unless otherwise stated in a credit line to the data. 
chickpea infection, despite the fact that, in a conducive environment, disease caused by Sclerotinia species can cause up to $100 \%$ chickpea yield loss $[4,5]$.

S. sclerotiorum is generally described as a necrotroph. As such, it derives its energy from dead plants to complete its lifecycle; this contrasts with biotrophs, which feed on living plant cells. However, recent studies indicate that S. sclerotiorum undergoes a brief biotrophic phase soon after penetration [6]. Expression of biotrophy-related genes, including those with Lysin Motif (LysM) domains, within the first $24 \mathrm{~h}$ postinoculation (hpi) during the S. sclerotiorum - B. napus interaction has been reported [7]. Furthermore, previous studies have shown that $S$. sclerotiorum integrin-like protein $(S S I T L)$ and chorismate mutase $(S s C m 1)$ may suppress host defence signalling during the biotrophic phase [6-8]. The pathogenesis journey through the two phases requires regulation of metabolic, virulence and defence enzymes in response to challenges associated with the type of host tissue, nature of energy source, acidity, and oxidative stress $[9,10]$.

The S. sclerotiorum reference genome has revealed several potential pathogenicity and virulence factors, including cell wall degrading enzymes (CWDES), metabolites, detoxification enzymes and candidate secreted effectors [11-13]. We refer to pathogenicity factors as genes that are essential for causing disease and virulence factors as genes that contribute in a quantitative manner to pathogen aggressiveness; any genes that have an impact on growth away from the plant host are referred to in this article as 'developmental factors', and these may also be pathogenicity or virulence factors at the same time [14-16]. Amselem et al. [13] compared the genomes of S. sclerotiorum and its relative $B$. cinerea and found a variety of putative secreted enzymes, including carbohydrate-active enzymes (CAZymes) such as xylanases, pectinases, polygalacturonases (PGs), hemicellulases, and cellulases. CAZymes play a crucial role in host cell wall degradation to simpler monomers that serve as a carbon source [17]. Disruption of the S. sclerotiorum CAZymes arabinofuranosidase/ $\beta$-xylosidase and an endo- $\beta-1,4$-xylanase showed reduced or lost virulence [18], an indication of their importance in the growth and virulence of the pathogen.

Secreted effector candidates have also been found in $S$. sclerotiorum. These are proteins that manipulate host cell functions and suppress plant defence to promote infection [13]. Some of these candidates have been functionally characterised. For example, secreted protein SSSSVP1 manipulates plant energy metabolism for full virulence [19]. Disruption of SsSSVP1 in S. sclerotiorum significantly reduces virulence in B. napus and Arabidopsis thaliana, compared to the wild type [19]. S. sclerotiorum strains lacking SSITL cause rapid induction of plant defence genes associated with the salicylic acid and jasmonic acid/ ethylene signalling pathway, suggesting SSITL as a possible effector that plays a key role in suppressing host immunity at an early stage of infection [6,20].

Transcription factors (TFs) act as pivotal regulators of gene expression by binding to gene promoters to activate or repress expression [15]. Several S. sclerotiorum transcription factors have been characterised. For example, in response to reduced acidity, the S. sclerotiorum gene encoding a zinc finger transcription factor ( $P a c 1)$ triggers oxalic acid (OA) biosynthesis, causing an increase in expression of exo-polygalacturonase (Sspg1), which is involved in pectin degradation, a significant constituent of the plant cell wall [21]. Although not directly involved in pathogenicity, Pac1 plays a role in OA and Sspg1 accumulation.

Recent studies of $S$. sclerotiorum gene expression on different hosts found that a gene encoding oxaloacetate acetylhydrolase (Ssoah1), known to be vital for OA production, was expressed in a similar pattern during infection of B. napus [5, 17] and P. vulgaris [22]. However, Ssoah1 expression was not observed during G. $\max$ infection [23]. Intrinsic host immunity may also affect the pattern of $S$. sclerotiorum gene expression as demonstrated in $B$. napus, where a gene encoding a polygalacturonase, Sspg1, was upregulated in a resistant variety, with no upregulation in a susceptible variety relative to in vitro [24]. These discrepancies indicate that S. sclerotiorum gene expression may depend on the host species and intraspecific differences in levels of resistance.

Our study aimed to (1) understand further how the $S$. sclerotiorum transcriptome is deployed in planta relative to in vitro conditions; (2) catalogue upregulated and downregulated genes in the S. sclerotiorum - chickpea pathosystem; and (3) evaluate the differences in gene regulation during $S$. sclerotiorum infection of a moderately resistant and a susceptible chickpea line. The current study hypothesised that (i) S. sclerotiorum would deploy an array of factors to facilitate chickpea infection and (ii) S. sclerotiorum will express genes that are specific to moderately resistant and susceptible varieties. This study reveals the activation of primary S. sclerotiorum pathogenesis factors, including CAZymes and affiliated proteins, putative secreted effector proteins, secondary metabolites and genes involved in regulating production of and tolerance to reactive oxygen species (ROS) such as catalases and peroxidases.

\section{Results and discussion}

\section{Processing and filtering of transcriptome data}

RNA-seq was used to compare S. sclerotiorum gene expression between samples taken during infection of two C. arietinum lines and during growth in vitro. Between 1.8 to $61.8 \%$ of sequence reads derived from the infected 
moderately resistant (MR) line samples, which were collected between 6 and $72 \mathrm{hpi}$, mapped to the reference genome of $S$. sclerotiorum. On the other hand, between 0.7 to $68.1 \%$ of sequence reads derived from infected susceptible line samples collected between 6- 72hpi mapped back to the $S$. sclerotiorum genome (Table 1). At $72 \mathrm{hpi}$, the average percentage of reads mapping to the fungal genome in the $S$ line was higher $(68.1 \%)$ than in the MR line (61.8\%), suggesting that the S line tissues may be more heavily colonised than those of the MR line (Table 1). The larger lesions found on the $\mathrm{S}$ line at the later stage of infection during the current study (results not shown) and greater abundance of fungal RNA in the $\mathrm{S}$ line samples together suggest that it exhibited greater levels of fungal colonisation than the MR line. Such differences have been reported in previous S. sclerotiorum transcriptome studies [5, 18, 19, 23].

The similarity of the three biological replicates and the accuracy of the RNA-seq analysis was demonstrated using classic multidimensional scaling (MDS), which shows the MDS plot of distances between gene expression profiles (Fig. 1). The MDS showed a distinct grouping of samples grown in vitro and in planta at the early (6-12 hpi), the mid (24 hpi) and late (48-72 hpi) stage of infection (Fig. 1). There was a clear distinction between the S. sclerotiorum transcriptomes at 24 and 48$72 \mathrm{hpi}$, an indication of the significant differences in the types of genes expressed at these time points.

\section{Validation of RNA-seq data using reverse transcription- quantitative PCR}

To validate the accuracy of the RNA-seq data, five upregulated genes and one downregulated gene in both chickpea lines at 12 hpi (early infection stage) and 48 hpi (late infection stage) were quantified using reverse transcription quantitative polymerase chain reaction (RT-qPCR) (Fig. 2). Six genes of which, according to RNA-seq analysis, five were significantly upregulated (sscle_05g041810, sscle_11g084430, sscle_08g067130, sscle_04g033880 and sscle_01g003110) and one was significantly downregulated (sscle_16g108230) were randomly selected for validation. These genes, their putative functions and the primer sequences are listed in Table S1. The expression patterns for each gene in our qPCR assay (Fig. 2a) were similar to the expression observed in the RNA-seq data (Fig. 2b). These results thus show a correlation between our qPCR and RNA-seq data.

\section{Genotype-specific and genotype non-specific differential gene expression during Sclerotinia sclerotiorum infection of chickpea}

Based on the distinct differences between the in planta and in vitro samples demonstrated in the MDS plot (Fig. 1 ), we expected that many $S$. sclerotiorum genes would be differentially expressed in planta relative to in vitro, irrespective of the susceptibility level of the host line. Therefore, we first assessed whether there were significant differences in read counts for each of the infection time points for each host relative to in vitro. We identified upregulation of 2150 and 3593 and downregulation of 7341 and 6894 S. sclerotiorum genes during MR and S line infection, respectively (Fig. 3a and b, Table S2, Figure S1). There were 171 common genes upregulated in MR line (Fig. 3a) and 230 common genes upregulated in $\mathrm{S}$ line (Fig. 3b). A comparative analysis of the upregulated genes between the MR and S genotypes during the

Table 1 Summary of the Illumina sequence reads generated by RNA - seq obtained from inoculation of a moderately resistant (MR) chickpea line PBA HatTrick and a susceptible (S) chickpea line Kyabra. The values for each time point are the averages of the three biological replicates

\begin{tabular}{|c|c|c|c|c|c|}
\hline \multirow[t]{2}{*}{ Host } & \multirow{2}{*}{$\begin{array}{l}\text { Hours post } \\
\text { inoculation } \\
\text { (hpi) }\end{array}$} & \multirow{2}{*}{$\begin{array}{l}\text { Total raw } \\
\text { read pairs }\end{array}$} & \multirow{2}{*}{$\begin{array}{l}\text { Trimmomatic } \\
\text { reads } \\
\text { retention (\%) }\end{array}$} & \multicolumn{2}{|c|}{ BBSplit reads separation } \\
\hline & & & & S. sclerotiorum & C. arietinum \\
\hline \multirow[t]{5}{*}{ MR } & 6 & $67,354,385$ & 98.7 & $1,207,201(1.8 \%)$ & $66,147,184(98.2 \%)$ \\
\hline & 12 & $68,680,857$ & 98.76 & $5,929,006(8.6 \%)$ & $62,751,851(91.4 \%$ \\
\hline & 24 & $61,114,985$ & 98.91 & $28,078,637$ (45.9\%) & $33,036,348(54.1 \%)$ \\
\hline & 48 & $56,616,306$ & 98.85 & 40,566,767 (71.7\%) & $16,049,538(28.3 \%)$ \\
\hline & 72 & $63,109,260$ & 98.92 & $39,012,318(61.8 \%)$ & $24,096,941(38.2 \%)$ \\
\hline \multirow[t]{6}{*}{ S } & 6 & $58,025,893$ & 98.4 & $414,371(0.7 \%)$ & $57,611,521(99.2 \%)$ \\
\hline & 12 & $72,896,961$ & 98.4 & $1,851,043(2.5 \%)$ & $71,045,918$ (97.5) \\
\hline & 24 & $54,049,381$ & 98.4 & $18,414,027(31 \%)$ & $35,635,354(65.9 \%)$ \\
\hline & 48 & $60,727,165$ & 98.5 & $36,714,863(60.4 \%)$ & $24,012,301(39.5 \%)$ \\
\hline & 72 & $57,636,636$ & 98.5 & $39,273,084(68.1 \%)$ & $18,363,551(31.9 \%)$ \\
\hline & & & & $* * 20,961,027$ & **40,875,050 \\
\hline In vitro & 0 & $56,566,082$ & 96.8 & $53,907,476(95.3 \%)$ & NA \\
\hline
\end{tabular}

\footnotetext{
**averages number of reads
} 


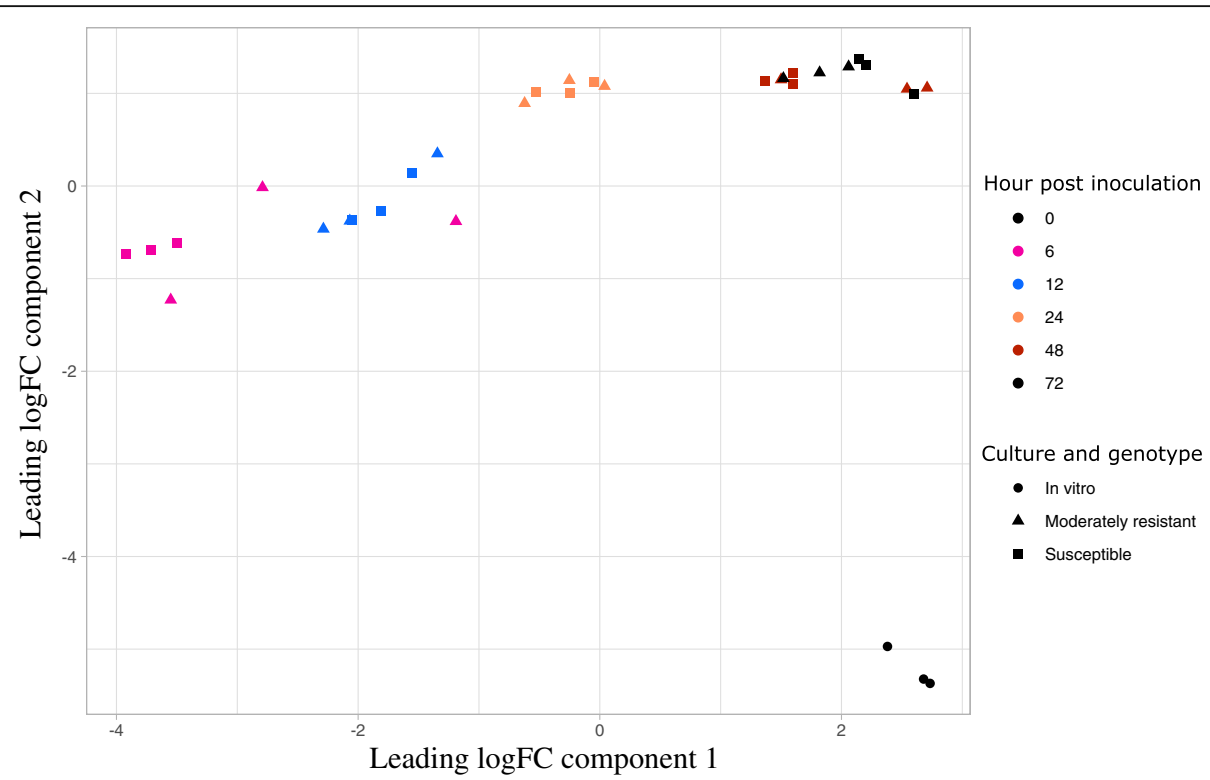

Fig. 1 A multidimensional scaling (MDS) plot showing the relatedness of Sclerotinia sclerotiorum samples used for RNA-Seq analysis. Samples were collected from moderately resistant (MR) and susceptible (S) chickpea lines at 6, 12, 24, 48 and $72 \mathrm{~h}$ post inoculation (hpi), as well as samples from an in vitro culture. The symbol $\mathbf{\Delta}$ represent the MR, $\boldsymbol{-}$ the $\mathrm{S}$ and $\bullet$ the in vitro samples. The $\mathrm{x}$ and $\mathrm{y}$-axis represent Euclidean dimensions, distinct colours represent each treatment, and individual dots represent each sample

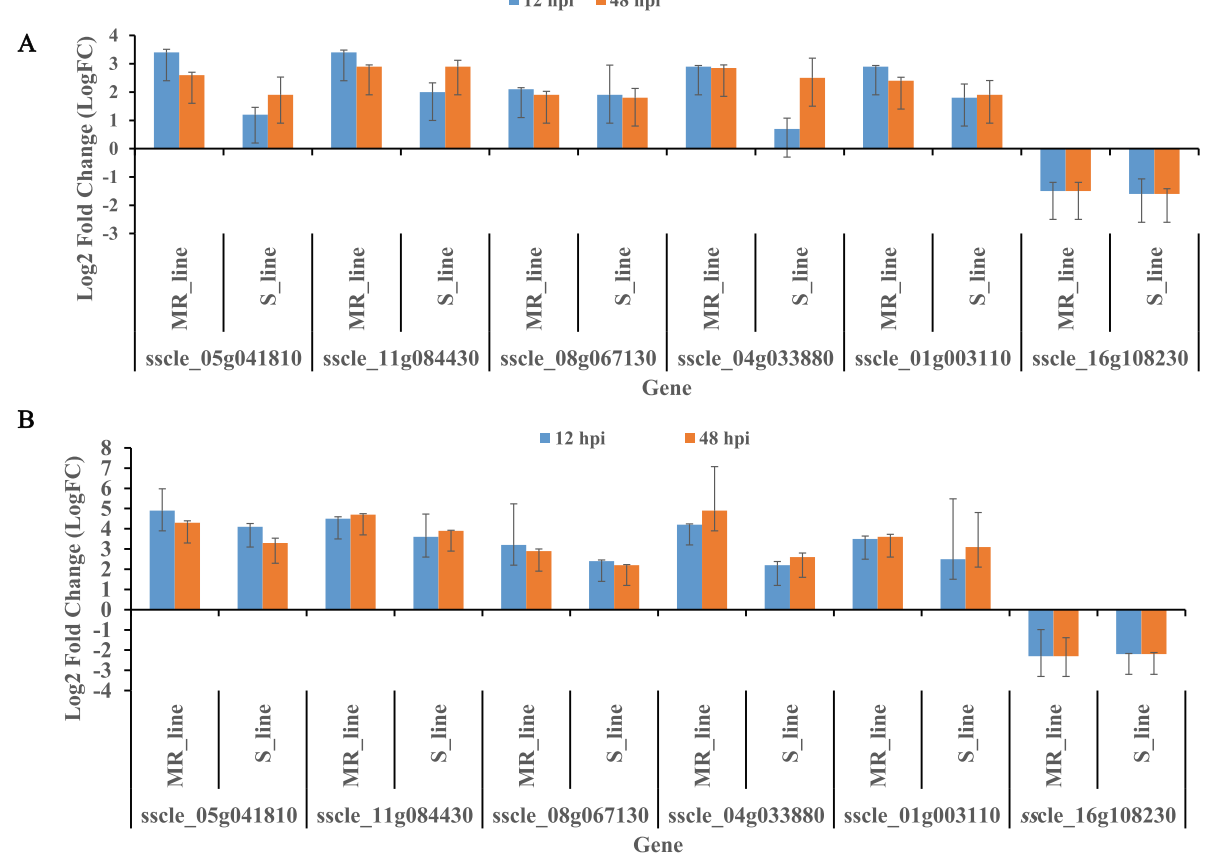

Fig. 2 Reverse transcription-quantitative PCR (RT-qPCR) validation of RNA sequencing (RNA-Seq) data in the moderately resistant (MR) and susceptible (S) chickpea lines following infection with Sclerotinia sclerotiorum. Log $_{2}$ (fold change) (LogFC) values were generated for qPCR samples by comparing the expression of genes at each time point of infection vs the in vitro control sample using the $2^{-\Delta \Delta C t}$ method (a). LogFC values were generated for RNA-Seq samples by comparing the average raw read counts at each time point of infection vs in vitro/vegetative growth culture (b). Pairwise contrasts were performed using quasi-likelihood F tests. The data are presented as means \pm standard error (SE) from three biological replicates for $12 \mathrm{hpi}$ (early stage of infection) and $48 \mathrm{hpi}$ (late stage of infection) 


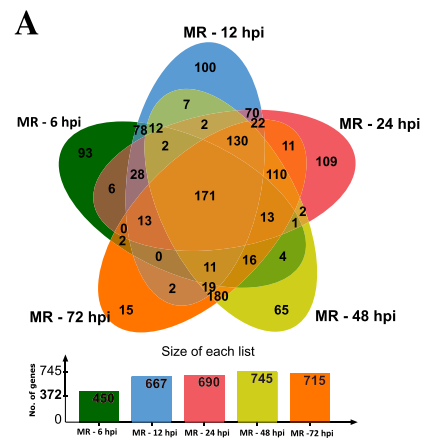

B
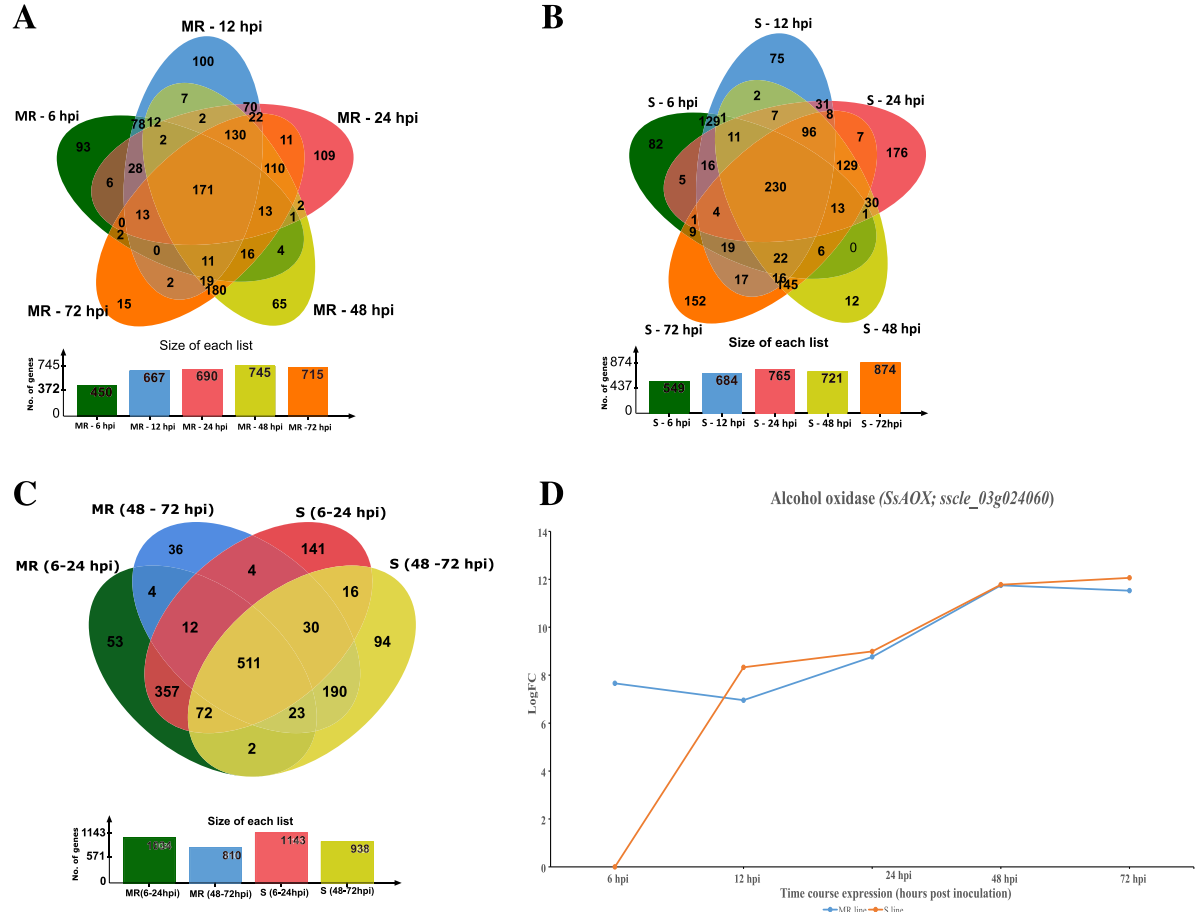

Fig. 3 Venn diagram and graph showing upregulated Sclerotinia sclerotiorum genes during interaction with chickpea. Venn diagram shows the number of common and unique genes at time points 6, 12, 24, 48, and 72 hpi in (a) moderately resistant (MR), and (b) susceptible (S) lines (c) Comparison of MR and $\mathrm{S}$ genes (d). A graph showing expression pattern during the time course of infection of the most highly expressed common gene between MR and S line

early stage (6-12 hpi) and late stage (48-72 hpi) of infection revealed that 511 genes were differentially expressed relative to in vitro at the same time points on both the MR and S lines (Fig. 3c). A gene encoding an alcohol oxidase (SsAOX; sscle_03g024060) was the most upregulated gene common to the two chickpea genotypes (Fig. 3d). An alcohol oxidase in Cladosporium fulvum has been suggested to be a key component in the detoxification of antifungal compounds released from the plant cell wall during infection [25]. Similarly, two putative hydrophobic cell surface proteins (sscle $12 \mathrm{~g} 091650 \quad(\log \mathrm{FC}=9.6-12.5)$ and sscle_09g070510 $(\operatorname{LogFC}=7.3-8.6)$ were the most highly upregulated at an early stage of infection relative to in vitro across both varieties. The gene sscle_12g091650 contains a hydrophobic surface binding protein A (HsbA) domain (PF12296) which was originally identified in Aspergillus oryzae as a surface protein that plays a key role in both the adhesion to and degradation of hydrophobic surfaces [26]. Similarly, sscle_09g070510 contains a repeated fasciclin domain (PF02469) which has been reported in Magnaporthe oryzae to be important in adhesion and binding to hydrophobic surfaces [27]. Our findings suggest these two genes might have a role during the $S$. sclerotiorum biotrophic phase during chickpea infection.
The current study describes genes upregulated in both the MR and $\mathrm{S}$ lines when compared to in vitro (Table S3). Comparing the transcription changes in the MR and $\mathrm{S}$ lines showed that there were also differences between lines in expression of some $S$. sclerotiorum genes relative to in vitro, with 82 and 251 genes upregulated exclusively in the MR or S line, respectively (Figure S2, Table S4). There were 42 genes with functional domains expressed either in the MR or S line only and these are involved in cell wall degradation, secondary metabolite biosynthesis, transport, detoxification, and signalling (Figure S2).

The common genes and these exclusively upregulated genes are discussed in various sections below. To note are two genes upregulated in the MR only which are involved in sugar glucose and carboxylate catabolism, metabolism and anabolism (sscle_01g005580 and sscle_ 05g040510) (Figure S2), indicating the importance of hydrolytic activities during infection of chickpea. Previous research has found pentose phosphate is critical in fungal pathogens for supplying cells with NADPH for detoxification of ROS and virulence [27, 28]. A gene involved in the pentose-phosphate pathway (sscle 01g005580) was upregulated in the MR line only. The full virulence of $S$. sclerotiorum requires detoxification of ROS, an important component of the host defence 
response [29], suggesting that S. sclerotiorum upregulation of sscle_01g005580 may be a managing strategy of host resistance responses.

Expression analysis of the MR versus $S$ line at each time point showed that genes with different expression relative to in vitro in the two lines (, there were only four genes that were differentially expressed between genotypes at any given time point (Table S2). This included two genes downregulated in the MR relative to the $S$ line (upregulated in the $\mathrm{S}$ line) at $6 \mathrm{hpi}$ and the other two upregulated in the MR relative to the $S$ line (downregulated in S line) at $48 \mathrm{hpi}$. The genes sscle_09g073140 $\left(\log F C=5.1, p_{a d j}=0.02\right)$ and sscle_04g033530 $(\log \mathrm{FC}=$ $\left.4.2, \mathrm{p}_{\mathrm{adj}}=0.04\right)$ were differentially expressed at $6 \mathrm{hpi}$ and sscle_16g111070 $\left(\operatorname{logFC}=5.3, \quad\right.$ padj $\left._{1}=0.004\right)$ and sscle $05 \mathrm{~g} 047520(\operatorname{logFC}=5.3)$ were differentially expressed at $48 \mathrm{hpi}$. These four genes are predicted in the S. sclerotiorum genome, but they have no known functional domains. Therefore, it is not possible to speculate much on their role during specific interactions between MR and $S$ chickpea genotypes.

We also performed an analysis where we included the genotype $\mathrm{x}$ timepoint interaction. The final design as a factor and found that this interaction was not significant for any genes $\left(P_{a d j}=0.05\right)$, suggesting that all genes had temporally similar expression patterns between the two lines. We did not include hosts (C. arietinum) differentially expressed genes in the current manuscript, as this will form a discrete study along with other data in future. However, the limited differences in expression of $S$. sclerotiorum genes between the two hosts would suggest that they present a qualitatively similar environment to the pathogen despite one of them, the MR line, reducing the extent of pathogen growth.

\section{Gene ontology term enrichment analysis of upregulated genes identifies multiple biological and molecular functions associated with infection}

Gene Ontology (GO) enrichment analysis is a powerful technique for analysing differential gene expression data to gain insight into the broader biological processes (BP), molecular functions (MF) and cellular components (CC) of genes. The upregulated genes were significantly enriched with wide range of GO categories (Table S5, Figure S3). The significant categories included those involved in oxidation-reduction process (GO:0055114), proteolysis (GO:0006508), organic substance metabolic process (GO: 0071704), and metabolic process (GO:0008152). GO enrichment analysis also showed significant enrichment of downregulated genes with wide range of GO categories including those involved in transmembrane transport (GO: 0055085), oxidoreductase activity (GO:0016491), drug metabolic process (GO:0017144), and $\mathrm{N}$-acyltransferase activity (GO:0016410) (Table S6, Figure S4).
The BPs highly enriched in the significantly upregulated set of genes, during the early stage of infection, included oxidation-reduction process (GO:0055114), protein metabolic process (GO:0019538), proteolysis (GO:0006508), cellular response to stimulus (GO:0051716) signal transduction (GO:0007165), carbohydrate metabolic process (GO:0005975) and metabolic processes (GO:0008152) (Table S5). Early defence of Aschochyta rabiei in chickpea has been associated with a strong accumulation of reactive oxygen species (ROS) in resistant chickpea cultivars compared to susceptible chickpea cultivars [30]. Similarly, previous research found $A$. thaliana enhanced host ROS increased resistance to $S$. sclerotiorum, and co-ordinately S. sclerotiorum genes involve in response to oxidative stress were overexpressed [31]. The BP category oxidation-reduction process (GO:0055114) was highly enriched exclusively in genes upregulated in the MR line at $6 \mathrm{hpi}$ and $48 \mathrm{hpi}$, suggesting that $S$. sclerotiorum may focus on regulating the environment redox status during MR line infection to counter host resistance responses.

GO term enrichment analysis also provided an insight into the temporal aspects of the S. sclerotiorum-chickpea interaction. Genes involved in cellular communication (GO:0007154), signalling (GO;0023052), response to stimulus (GO:0050896), and signal transduction (GO: 0007165) (Table S5, Figure S3) were enriched in genes upregulated in both lines at the early stage of infection (6-24 hpi; Fig. 3c), indicating the importance of rapid adaptation to in planta growth. Among genes upregulated in both lines at the late stage of infection (48-72 hpi; Fig. 3c), the enriched GO categories included carbohydrate metabolic process (GO:0005975), and metabolic process (GO: 0008152) (Table S5, Figure S3) among others, an indication of the importance of utilisation of energy sources during the necrotic phase of S. sclerotiorum infection. The most significantly enriched GO categories in the current study grouped into carbohydrate-active enZYmes (CAZymes), proteases, transporters, transcription factors and other secondary metabolites. Genes were categorised based on their functions and predicted roles to simplify the study, as discussed below.

\section{Genes involved in the degradation of the host cuticle}

The plant cuticle is the first physical barrier to pathogen invasion and is composed of lipid-derived polyester and cuticular waxes [32]. In the current study, S. sclerotiorum genes encoding cutinases and lipases were upregulated throughout infection. Interestingly, four $S$. sclerotiorum genes encoding lysophospholipase (sscle 02g020060), carboxylesterase (sscle_03g027590), GDSLlipase-acylhydrolase (sscle_01g004820), and triacylglycerol lipase (sscle_01g008640) were significantly upregulated at the late stage of infection, specifically in the $\mathrm{S}$ line (Table S7). This suggests the induction of lipolytic 
enzymatic activity in S. sclerotiorum may depend on the immunity of the host. Lipases were also reported to act as virulence factors in the fungal phytopathogen $B$. cinerea [33], suggesting S. sclerotiorum lipases may play a role in virulence.

\section{Genes involved in the degradation of the host cell wall} As a necrotroph, degradation of the host cell wall is important during S. sclerotiorum infection to achieve the required plant cell death for growth and development [34]. A portion of the numerous cell wall degrading enzymes (CWDEs) identified in the S. sclerotiorum genome [15], including those involved in the degradation of lipids, cellulose, arabinogalactan, hemicellulose, mannan, pectin, starch and proteins, were upregulated during infection of chickpea (Table 2, Table S7). After breaching the cuticle, polygalacturonases (PGs) are often the first lytic enzymes produced by a pathogen $[35,36]$. A putative exo-PG (sscle_05g046840, $\operatorname{LogFC}=3.2-8.2$ ) was the most upregulated relative to in vitro in the current study in both chickpea varieties relative to in vitro throughout the infection (Table S7). Four previously characterised PGs: endo-PGs Sspg1 (sscle_16g108170) and Sspg3 (sscle_09g070580), and exo-PGs Ssxpg1 (sscle_ 02g018610) and Ssxpg2 (sscle_04g035440) were also upregulated in the current study, relative to in vitro (Table S7). Infiltration of purified endo-PG into plant leaf tissues causes rapid loss of cell wall integrity followed by cell death, [37, 38] suggesting the importance of Sspg1 and Sspg3 in tissue maceration during S. sclerotiorum infection. Orthologs of Ssxpg1 and Ssxpg2 in B. cinerea (BcPG1 and BcPG2) showed necrosis inducing activities, and disruption of either of the genes reduced virulence $[28,39]$, an indication of the significant role exo-PGs play in lesion development and host colonisation.

Proteases are hydrolytic enzymes that act as important virulence factors in many fungal plant pathogens by degrading host proteins that are involved in the immune response [40]. The in planta upregulation relative to in vitro of non-aspartyl acid protease (acp1; sscle $11 \mathrm{~g} 082980)$ was observed at all time points, peaking in expression at $24 \mathrm{hpi}$ in both lines $(\operatorname{LogFC}=7.2-7.9)$ (Table S7). Several factors control acp1 induction, including glucose levels, nitrogen starvation and acidification [21]. Previous studies found upregulation of acp1 at a later stage of $S$. sclerotiorum infection in $H$. annuus cotyledons [21], G. max petioles [23], and B. napus leaves [7], suggesting that $a c p 1$ has a possible role in virulence on multiple plant species and that it responds to cues present at different infection stages in different hosts. Another gene encoding an aspartyl protease, sscle_07g058540, was upregulated at all stages of infection in the current study, with a peak expression relative to in vitro at $24 \mathrm{hpi}$ (Table S7). The gene sscle 07g058540 is a homologue of several aspergillopepsinlike proteins (cd06097) in aspergillosis of humans, which act as a cofactor for the persistence of colonisation [41]. Putting this all together, sscle_07g058540 may be a catalyst that assists S. sclerotiorum growth and development during infection.

\section{S. sclerotiorum secondary metabolite synthesis and detoxification enzymes}

Secondary metabolite (SM) polyketide synthases (PKSs) and non-ribosomal peptide synthases (NRPSs) were the major enzymes associated with SM synthesis in S. sclerotiorum and make up to $47.2 \%$ of the upregulated SM biosynthesis clusters in the current study (Table S8). The SM biosynthesis gene expressed at the highest level $(\operatorname{LogFC}=7.6-9.2)$ was a gene encoding the PKS responsible for dihydroxy naphthalene (DHN) melanin biosynthesis (PKS13; sscle_03g031520) at 6-12 hpi as compared to the in vitro control, indicating a possible role in penetration during chickpea infection (Table S8). In a previous study, disruption of $S$. sclerotiorum genes involved in melanin biosynthesis showed no change in pathogenicity; however, slower development of mycelial and hyphal branching was observed [42]. The current results indicate the importance of melanin to aid appressoria mediated penetration of S. sclerotiorum.

Glutathione S-transferases (GSTs) play critical roles in the detoxification of xenobiotic chemicals in fungi by

Table 2 The number of in planta upregulated S. sclerotiorum genes involved in the cell wall and cuticle degradation

\begin{tabular}{lll}
\hline Substrate & CWDE category & Number of upregulated genes in the category \\
\hline Lipid/cutin & Cutin & 14 \\
Polysaccharides & Cellulose & 19 \\
& Arabinogalactan & 6 \\
& Hemicellulose & 16 \\
& Mannan & 7 \\
& Pectin & 16 \\
Proteins/peptides & Starch & 3 \\
\hline
\end{tabular}


Table 3 Sclerotinia sclerotiorum detoxification enzymes upregulated (LogFC) in planta relative to in vitro

\begin{tabular}{|c|c|c|c|c|c|c|c|c|c|c|c|}
\hline \multirow[b]{2}{*}{ Gene ID } & \multirow[b]{2}{*}{ Description } & \multicolumn{5}{|c|}{ MR $^{\mathrm{a}}$ line hpi ${ }^{*}$} & \multicolumn{5}{|c|}{$\mathrm{S}^{\mathrm{b}}$ line $\mathrm{hpi} \mathrm{i}^{*}$} \\
\hline & & 6 & 12 & 24 & 48 & 72 & 6 & 12 & 24 & 48 & 72 \\
\hline sscle_01g003110 & Glutathione S-transferase & 3.6 & 3.5 & 4.9 & 3.6 & 4.1 & - & 2.5 & 5.2 & 3.1 & 3.8 \\
\hline sscle_01g005000 & Glutathione S-transferase & - & - & 3.7 & 3.1 & 2.9 & - & - & 3.2 & - & - \\
\hline sscle_08g067590 & Glutathione S-transferase & - & - & - & 2.8 & 2.9 & - & - & - & - & - \\
\hline sscle_02g021570 & Laccase & 4.3 & - & - & - & - & 4.6 & 4.5 & - & - & - \\
\hline sscle_01g005590 & Cytochrome P450 & - & - & - & 3.3 & 2.9 & - & - & - & 2.9 & 3.1 \\
\hline sscle_04g033880 & Cytochrome P450 & 4.1 & 4.2 & 5.6 & 4.9 & 5.9 & - & 2.2 & 2.3 & 2.6 & 5.7 \\
\hline
\end{tabular}

${ }^{a}$ moderately resistant line; ${ }^{b}$ susceptible line; ${ }^{*}$ hpi $=$ hours post-inoculation

reducing them to glutathione [43]. The S. sclerotiorum GST most upregulated relative to in vitro in this study was a UDP-glucosyltransferase (Ssbgt1; sscle_01g003110, $\operatorname{LogFC}=3.6-5.2$ ) (Table 3). Ssbgt1 plays a role in the degradation of the antimicrobial compound brassinin through glycosylation and is induced in response to the presence of a variety of plant phytoalexins [44].

Other GSTs induced in planta in the current study were sscle_01g005000 $(\operatorname{logFC}=2.9-3.7)$ in both lines and sscle_08g067590 $(\log \mathrm{FC}=2.8-2.9)$ in the MR line, at 24-72 hpi (Table 3). Disruption of GST genes AbGSOT1 and AbUre $2 p B 1$ in the host generalist brassica pathogen Alternaria brassicicola led to reduced virulence [45]. This indicates the importance of xenobiotic compound detoxification during fungal infection. The greatest upregulation of GSTs was observed in the MR line, possibly a reflection of host resistance exerted by the release of host defence-related antifungal compounds during infection.

Benzoic acid derivatives are aromatic compounds arising from the plant defence $\beta$ - ketoadipate pathway [46]. The CYP enzyme, benzoate 4-hydroxylase, from Aspergillus niger, was reported to play a role in the hydroxylation of benzoic acid to 4-hydroxybenzoate [47]. An $S$. sclerotiorum CYP gene, sscle_01g005590, encoding benzoate 4-hydroxylase, was upregulated at 48-72 hpi in both chickpea lines (Table 3), which may suggest higher pressure from host defence toxins at the late stage during S. sclerotiorum-chickpea interaction.

\section{Sclerotinia sclerotiorum signalling pathways are vital during chickpea infection}

A total of 24.S. sclerotiorum transcription factors were upregulated in the current study (Table S9). Two functionally characterised S. sclerotiorum TFs Pac1 (sscle 06g049830) [48], and Ssfkh1 (sscle_06g049780) [49] were upregulated in planta. Pac1 was upregulated at $12 \mathrm{hpi}$ in the $\mathrm{S}$ line only $(\log \mathrm{FC}=2.8)$ during chickpea infection (Table S9). Pac1 triggers oxalic acid (OA) biosynthesis in response to increased $\mathrm{pH}$ and reduces the ambient $\mathrm{pH}$, which in turn causes an increase in Sspg1 and acp1 expression and promotes sclerotial development [48].
The upregulation of $\mathrm{Pacl}$ on the $\mathrm{S}$ line may suggest that $\mathrm{S}$ line tissues were more alkaline than those of the MR line.

Fungal histidine kinases play a vital role in controlling signalling pathways that regulate osmotic and oxidative stress responses, cell cycle control and virulence [15]. We found that the two-component sensor histidine kinase Shk1 (sscle_16g107650) was upregulated at 12-72 hpi relative to inoculum in both lines (Table S9). A previous study showed disruption of Shk1 led to reduced and altered hyphal growth and failed sclerotia formation [50]. Although Shk1 mutants exhibited normal virulence, they showed sensitivity to osmotic stress and increased resistance to fungicides, which suggest that Shk1 likely works upstream of the MAPK cascade to control these processes.

\section{A substantial portion of putative effectors are upregulated on both host varieties during infection}

We compared the $S$. sclerotiorum expressed genes with the 523 secreted proteins identified in the $S$. sclerotiorum genome [13] to determine specific temporal changes in their regulation during chickpea infection. Of these, 173 were upregulated in both varieties, and 148 downregulated, with nine of the upregulated genes observed in the MR variety only and 27 in the $S$ variety only (Table S10). Of the identified S. sclerotiorum secreted proteins, 78 were predicted to be candidate effectors by Guyon et al. [51] and 70 by Derbyshire et al. [13]. Of these candidate effectors, 32 were upregulated and 40 downregulated on both hosts during the current study (Table S11).

In addition to putative candidate effectors, we also considered the expression of experimentally characterised S. sclerotiorum effectors. Previous studies showed that $S$. sclerotiorum small cysteine-rich secreted protein SsSSVP1 (sscle_01g003850) plays an essential role during infection by interfering with host respiration and inducing localised tissue necrosis [19]. In the current study, SsSSVP1 was upregulated at $48 \mathrm{hpi}$ in the MR line and $72 \mathrm{hpi}$ in the $\mathrm{S}$ line $(\log \mathrm{FC}=5.1$ and 5.7$)$, respectively (Table S11). S. sclerotiorum SsSSVP1 mutants showed reduced virulence in B. napus and A. thaliana [19]. 
Similarly, SsSSVP1 upregulation was previously reported during the late stage of infection in B. napus $[5,17]$ and at all-time points in G. $\max$ [23]. The earlier induction SsSSVP1 of in the MR line (48 hpi) compared to the S line (72 hpi) may suggest that temporal regulation of expression of SsSSVP1 may depend on host susceptibility level.

Two S. sclerotiorum necrosis and ethylene-inducing (NEP) proteins (SsNEP1 and SsNEP2) were characterised in a previous study on Nicotiana benthamiana and were reported to function as necrotrophic effectors [52]. The previous study showed upregulation of both genes at mid to later stages of infection with SsNEP2 expressed at a higher level than SsNEP1. In the current study, SsNEP1 (sscle_04g039420) was not differentially expressed, and SsNEP2 (sscle_12g090490) was upregulated at the later stages of infection (48 hpi in MR and at 48-72 hpi In $\mathrm{S}$ lines) relative to in vitro (Table S11). Orthologs of these two genes in B. cinerea ( $B C N E P 1$ and $B c N E P 2)$ are both proteins capable of inducing necrosis in dicotyledonous but not monocotyledons host [53].

\section{Expression of genes related to oxalic acid production and reactive oxygen species regulation}

Oxalic acid (OA) has roles in weakening the host cell wall, activating hydrolytic enzymes, suppressing the oxidative burst and intensifying programmed cell death (PCD), leading to full colonisation [54]. A gene encoding oxalate decarboxylase (Ss-odc2: sscle_09g069850) was highly upregulated at the very early stage (6-24 hpi) of infection $(\operatorname{LogFC}=6.5-8.4)$ and showed lower expression at the later stage $(\operatorname{LogFC}=3.8-4.2)$ of infection relative to in vitro, in both chickpea lines (Table 4). Ss$o d c 2$ protects the pathogen cells by preventing excess accumulation of OA [55]. A previous study suggested that an alternative route of OA biosynthesis may be utilised during S. sclerotiorum early stages of infection [56]. Expression of Ss-odc2 without the induction of Ssoah1 in the current study may support previous findings that $\mathrm{OA}$ is not the only source of acidification or determinant of S. sclerotiorum virulence expression [57], or alternatively, the host tissue was already acidic enough for growth.

An S. sclerotiorum gene, sscle_09g069850, with a bicupin domain, was previously reported to be a possible oxalate oxidase enzyme [58]. This gene was highly upregulated at $6-12 \mathrm{hpi}(\operatorname{logFC}=7.6-8.7)$ and expression decreased at $48-72$ hpi $(\operatorname{logFC}=3.8-4.2)$ with no expression at $24 \mathrm{hpi}$, in both chickpea lines, relative to in vitro (Table 4). A previous study suggested that oxalate oxidases play a role in inducing programmed cell death [54]. The pattern of sscle_09g069850 expression in the current study may suggest involvement in both the biotrophic and necrotic stages during chickpea interaction.

Catalases and peroxidases are also important S. sclerotiorum ROS scavengers [59]. Three catalases, sscle 03g026200 (Sscat1), sscle_04g037170, and sscle_ $15 \mathrm{~g} 104430$, were upregulated during the late stage of infection (48-72 hpi) in the MR and $72 \mathrm{hpi}$ in the $S$ line (Table 4). The most upregulated catalase during the current study was the previously characterised Scat1 (sscle_04g037170). Scat1 mutants show slower radial growth, a higher number of small sclerotia and hypovirulence [60]. The upregulation of catalases and peroxidases was observed at an early stage in the MR line and later stage in the $S$ line during infection, suggesting $S$. sclerotiorum induces ROS scavengers depending on the host speed of employing defence responses.

\section{Conclusion}

Our study demonstrates a continuum of activities that occurs during infection and colonisation of $C$. arietinum by $S$. sclerotiorum. In support of our study hypothesis, we observed significant upregulation of S. sclerotiorum genes in planta irrespective of the host's susceptibility

Table 4 Sclerotinia sclerotiorum reactive oxygen scavenging (ROS) enzymes upregulated (LogFC) during chickpea infection relative to in vitro

\begin{tabular}{|c|c|c|c|c|c|c|c|c|c|c|c|}
\hline \multirow[b]{2}{*}{ Gene ID } & \multirow[b]{2}{*}{ Description } & \multicolumn{5}{|c|}{ MR $^{a}$ line hpi* } & \multicolumn{5}{|c|}{$\mathrm{S}^{\mathrm{b}}$ line $\mathrm{hpi}^{*}$} \\
\hline & & 6 & 12 & 24 & 48 & 72 & 6 & 12 & 24 & 48 & 72 \\
\hline sscle_15g104430 & Catalase & - & - & - & 5.1 & 5.7 & - & - & - & - & 4.5 \\
\hline sscle_04g037170 & Catalase & - & - & - & 5.6 & 5.8 & - & - & - & - & 4.7 \\
\hline sscle_03g026200 & Catalase & - & - & - & - & - & - & - & - & - & 2.9 \\
\hline sscle_09g069850 & Oxalate decarboxylate & 8.4 & 6.5 & - & 4.1 & 4.2 & 8.2 & 8.1 & - & - & 3.8 \\
\hline sscle_04G035020 & Peroxidase & - & 3.5 & 3.5 & 4.3 & 5.1 & - & - & 5.3 & 5.4 & 4.7 \\
\hline sscle_15g102360 & Peroxidase & 3.6 & - & - & - & - & 4.1 & 3.8 & - & - & - \\
\hline sscle_09g070530 & Peroxidase & 4.1 & - & - & - & - & - & 3.6 & - & - & 3.6 \\
\hline sscle_08g065740 & Peroxidase heme-thiolate & 4.5 & - & - & - & - & 4.6 & - & - & - & - \\
\hline
\end{tabular}

${ }^{a}$ moderately resistant line; ${ }^{b}$ susceptible line; ${ }^{*} \mathrm{hpi}=$ hours post-inoculation 
level. To our knowledge, this is the first RNA-seq study to investigate in planta gene expression in S. sclerotiorum during $C$. arietinum infection. The current findings showed that $S$. sclerotiorum induced numerous virulence factors, including CAZymes, transportation enzymes, detoxification enzymes, metabolites and putative secreted effector proteins during penetration and subsequent proliferation through the host.

In conclusion, the present study provides an insight into global transcriptional changes in S. sclerotiorum during infection of chickpea varieties differing in their susceptibility to the pathogen. Our findings further emphasise the role of CAZymes and proteases, in addition to secreted effectors, transporters and detoxifying enzymes during the growth and development of S. sclerotiorum within chickpea plants. Temporal changes in expression have demonstrated that $S$. sclerotiorum specific gene expression may depend on host susceptibility level. Detailed investigation of the identified genes could elucidate their precise roles and to determine if they represent viable targets for disease management.

\section{Material and methods}

\section{Plant material}

Two chickpea desi varieties with different levels of susceptibility to $S$. sclerotiorum were used as hosts in this study [61]. Seeds of moderately resistant (PBA HatTrick) and highly susceptible (Kyabra) chickpea varieties were planted in $5 \mathrm{~cm}$ pots with an all-purpose potting mix (UWA mix, Richgro, Perth, Australia) and grown for 8 weeks in a plant growth chamber with a 16 -h photoperiod, a $22 / 16^{\circ} \mathrm{C}$ day/night temperature, and $60 \%$ relative humidity. Once germinated, seedlings were watered as necessary and fertilised at 4 weeks with Nitrophoska perfekt $^{\text {tm }}$ fertiliser (Incitec Pivot fertilisers, Victoria, Australia). These two varieties are herein referred to as the MR line (moderately resistant PBA HatTrick) and S line (susceptible Kyabra).

\section{Fungal material preparation and inoculation}

An aggressive $S$. sclerotiorum isolate CU8.20 was previously found to be aggressive in B. napus [62] and chickpea [61]. The isolate CU8.20 culture was prepared from dry sclerotia, which were cut in half and placed mycelium-side down on potato dextrose agar (PDA) (Becton Dickinson, USA) and incubated at $20^{\circ} \mathrm{C}$ for $5-7$ days in the dark plates. Subsequently, a mycelial plug was cut from actively growing edges of the PDA culture and sub-cultured in a fresh PDA plate at $20^{\circ} \mathrm{C}$ for two days. Only plates with consistent mycelial growth were used for inoculation. Eight-week-old plants were infected following a stem inoculation assay that involved cutting a $5 \mathrm{~mm}$ plug from the actively growing mycelium and placing it in the middle of the plant stem. The plug was secured using Parafilm ${ }^{\circ}$ to maintain moisture. The in vitro control samples were generated by inoculating potato dextrose broth (PDB) with 5 $\mathrm{mm}$ minimal media agar plugs and incubated at $26^{\circ} \mathrm{C}$ with shaking at $160 \mathrm{rpm}$ for $96 \mathrm{~h}$.

\section{Sample collection}

S. sclerotiorum mycelium (in vitro samples) was collected from PDB and flash-frozen in liquid nitrogen. Inoculated plant stem sections were collected by cutting the stem $1 \mathrm{~cm}$ above and below the point of inoculation or the lesion at six, $12,24,48$, and $72 \mathrm{~h}$ post-inoculation (hpi), immediately put in an Eppendorf tube and flashfrozen in liquid nitrogen within $10 \mathrm{~s}$ of collection and stored at $-80^{\circ} \mathrm{C}$ until RNA extraction. Each treatment (time point /variety) consisted of three biological replicates. Six stem sections were collected from four individual plants and pooled for one biological replicate.

\section{RNA extraction and sequencing}

The fungal mats and the infected stem samples were ground into a fine powder with liquid nitrogen pre-cooled in an RNAse-free mortar and pestle. Total RNA was extracted from inoculated chickpea stem tissues and $S$. sclerotiorum mycelium following the Trizol $^{\mathrm{Tm}}$ Reagent protocol (Invitrogen Corp., Carlsbad, CA, USA). RNA quantity and quality were assessed using the Qubit fluorometry assay (Invitrogen Corp., Carlsbad, CA, USA). Novogene performed library preparation (150 bp paired-end) and sequencing on an Illumina HISEq 2500 platform.

\section{RNA sequencing data quality control}

Quality assessment on raw fastq reads and cleaned reads was conducted using the FastQC tool (V. 0.11.8) (www. bioinformatics.babraham.ac.uk/projects/fastqc). Trimmomatic v.0.38 was used to trim low-quality base calls, and filter adapters and low quality reads [63]. The following trimmomatic parameters were used, ILLUMINACLIP: TruSeq3-SE: 2:30:10 MINLEN: 36 LEADING: 3 TRAILING: 3 SLIDINGWINDOW: 4:15.

\section{Read alignment}

The trimmed reads were split between the pathogen $(S$. sclerotiorum strain 1980 genome, Bioproject PRJNA348385, assembly ASM185786v1) [13] and the host (Cicer arietinum, Bioproject PRJNA190909, assembly ASM33114v1) [64] using BBSplit tool v.38.12 (https:// sourceforge.net/projects/bbmap/). Quality filtered $S$. sclerotiorum in planta and in vitro reads were aligned to the reference genomes using HISat2 v2.1.0 [65]. The resulting alignments in SAM format were then converted to BAM format, sorted and indexed using SAMtools v.0.1.19 [66]. The number of reads that mapped to each gene in the reference (read counts/gene counts) were generated using HTseq package v 0.12.4 [67]. 


\section{Differential gene expression analysis}

The S. sclerotiorum in planta differential gene expression analysis was conducted using edgeR and limma Bioconductor packages in $\mathrm{R}$ v4.0.2 [68, 69]. The raw count data were normalised using the Trimmed Mean of Mvalues (TMM) method. Principle coordinate analysis (PCoA) plots were generated using the plot-MDS () function from limma and the heatmap.2 () function from gplots to determine the relatedness of the biological replicates. Pairwise contrasts were performed using quasi-likelihood $\mathrm{F}$ tests [70]. A false discovery rate (FDR) cut-off of 0.05 was applied, and a $\log _{2}$ fold change cutoff of $\geq 2$ to indicate upregulation and $\leq-2$ to indicate down-regulation. Differentially expressed genes (DEGs) were considered at each time point for each host in relation to the in vitro/vegetative growth culture (hypothetical time-point 0 ).

\section{Gene ontology enrichment analysis of DEGs}

S. sclerotiorum Gene ontology (GO) terms were derived from a previous InterPro annotation [13]. To test for significantly enriched gene ontology $(\mathrm{GO})$ categories, we used the R Bioconductor package TopGO (2007) to implement the classical method and Fisher's exact test with a $P$-value threshold of $\leq 0.05$ [71]. GO terms for the full $S$. sclerotiorum total gene list were used as the background list for enrichment analysis.

\section{CAZymes and secreted protein effector analysis}

CAZymes were predicted using DBCan2 web server v8.0 [72]. The S. sclerotiorum strain 1980 protein sequences were used as the input for CAZymes prediction (GCA 001857865) [13]. The CAZymes prediction was made using three databases, HMMER, DIAMOND and Hotpep [72]. Only those CAzymes identified by at least two databases and with positive SignalP scores were considered for analysis. This study considered previously predicted effectors by Derbyshire et al. [13] and Guyon et al. [51].

\section{Validation of RNA-seq data using reverse transcription- quantitative PCR}

RNA-Seq data was validated by performing reverse transcription quantitative polymerase chain reactions (RTqPCRs) on five upregulated genes and one downregulated gene. Two-time points were chosen to represent the early stage $(12 \mathrm{hpi})$ and late stage $(48 \mathrm{hpi})$ of MR and $\mathrm{S}$ line infection. RNA samples used for qPCR validation were the same samples used for Illumina sequencing. The RNA samples were reverse transcribed using the First-Strand cDNA Synthesis Kit for RT-PCR (AMV) (NEB Inc. Ipswitch, MA) according to the manufacturer's instruction. The cDNA samples were then diluted 1:20 before qPCR. Real-time quantification for MR line was performed with iTaq Universal SYBR Green Supermix and S line with PowerUp SYBR Green master mix with the following cycling conditions: $95^{\circ} \mathrm{C}$ for $2 \mathrm{~min}$, then $95^{\circ} \mathrm{C}$ for $15 \mathrm{~s}, 60^{\circ} \mathrm{C}$ for $30 \mathrm{~s}$ and $72^{\circ} \mathrm{C}$ for $15 \mathrm{~s}$, repeated 40 cycles, followed by $72{ }^{\circ} \mathrm{C}$ for $2 \mathrm{~min}$. The relative expression of genes was calculated using the $2^{-\Delta \Delta \mathrm{Ct}}$ method [73] with the fungal $\beta$-tubulin gene (sscle $02 \mathrm{~g} 015170$ ) used as an endogenous control. Three biological replicates were used, and three technical replicates per biological replicate to determine the expression levels for the six genes relative to fungal $\beta$-tubulin. The qPCR experiment consisted of three biological replicates per sample and three technical replicates per biological replicate.

\section{Abbreviations}

CAZymes: Carbohydrate-active enzymes; CWDE: Cell wall-degrading enzymes: CYP450: Cytochrome 450; DEG: Differentially expressed genes; FDR: False discovery rate; GO: Gene ontology; GST: Glutathione $S$ - transferase; LogFC: Log 2 fold change; MR: Moderately resistant; OA: Oxalic acid; PCD: Programmed cell death; PDA: Potato dextrose agar; PG: Polygalacturonase; PKS: Polyketide synthase; ROS: reactive oxygen species; S: Susceptible; SM: Secondary metabolites; SSR: Sclerotinia stem rot; TF: Transcription factor

\section{Supplementary Information}

The online version contains supplementary material available at https://doi. org/10.1186/s12864-021-07655-6.

Additional file 1: Table S1. Primers used in the validation of RNA sequencing data.

Additional file 2: Table S2. List of differentially expressed S. sclerotiorum genes during the interaction with moderately resistant (MR) and susceptible (S) chickpea lines at 6, 12, 24, 48 and 72 hours post inoculation ( $P$. Adj. <0.05; LogFC $\geq 2$ indicated upregulated or $\geq 2$ indicate downregulated.

Additional file 3: Table S3. List of common S. sclerotiorum genes differentially expressed during the interaction with moderately resistant (MR) and susceptible (S) at 6, 12, 24,48 and 72 post inoculation relative to in vitro.

Additional file 4: Table S4. List S. sclerotiorum genes differentially expressed exclusively in moderately resistant (MR) only and susceptible (S) only at $6,12,24,48$ and 72 post inoculation relative to in vitro during chickpea infection

Additional file 5: Table S5. Enrichment analysis of S. sclerotiorum upregulated genes during interaction with moderately resistant (MR) and susceptible (S) chickpea lines at 6, 12, 24, and 72 hours post inoculation relative to in vitro control.

Additional file 6: Table S6. Enrichment analysis of S. sclerotiorum downregulated genes during interaction with moderately resistant (MR) and susceptible (S) chickpea lines at 6, 12, 24, and 72 hours post inoculation relative to in vitro control.

Additional file 7: Table S7. Description of temporal S. sclerotiorum in planta upregulated genes involved in cell wall degradation during chickpea infection relative to in vitro control (P. Adj. <0.05; LogFC $\geq 2$ ).

Additional file 8: Table S8. Secondary metabolite synthesis, cytochrome P450 and transporter genes upregulated at some timepoint of the MR and $S$ lines infection in comparison to in vitro control ( $P$. Adj. $<0.05$; $\log F C \geq 2$ ).

Additional file 9: Table S9. S. sclerotiorum transcriptional factors which were upregulated at some timepoint of the MR and $S$ lines infection in comparison to in vitro control ( P. Adj. <0.05; LogFC $\geq 2$ ). 
Additional file 10: Table S10. Secreted proteins upregulated and downregulated during the course of MR and $\mathrm{S}$ lines infection.

Additional file 11: Table S11. Predicted S. sclerotiorum putative effector candidate's upregulated at some timepoint MR and $\mathrm{S}$ lines infection relative to in vitro control (P. Adj. <0.05; LogFC $\geq 2$ ).

Additional file 12: Figure S1: Differentially expressed genes in MR and $\mathrm{S}$ line at $6,12,24,48$ and $72 \mathrm{hpi}$ based on expression pattern relative to in vitro (P. Adj. < 0.05; LogFC upregulated $\geq 2$ and downregulated $\leq$ 2). The colours indicate the fold change with red $=$ upregulated, black $=$ regulated and green $=$ downregulated genes.

Additional file 13: Figure S2: Differentially expressed genes exclusively in MR only and S line only at 6, 12, 24, 48 and 72 hpi based on expression pattern relative to in vitro (P. Adj. < 0.05; LogFC upregulated $\geq$ 2 and downregulated $\leq 2$ ). The colours indicate the fold change with red $=$ upregulated, black $=$ regulated and green $=$ downregulated genes

Additional file 14: Figure S3: Heatmap showing the top $20 \mathrm{GO}$ categories of upregulated genes at 6, 12, 24, 48 and 72 hpi in a moderately resistant (MR) and susceptible (S) chickpea lines based on log(10)fold change (enrichment). The colours indicate the enrichment with green $=$ high enrichment, and red $=$ low enrichment.

Additional file 15: Figure S4: Heatmap showing the top $20 \mathrm{GO}$ categories of downregulated genes at 6, 12, 24, 48 and $72 \mathrm{hpi}$ in a moderately resistant (MR) and susceptible ( $\mathrm{S}$ ) chickpea lines based on log(10)fold change (enrichment). The colours indicate the enrichment with green $=$ high enrichment, and red $=$ low enrichment.

\section{Acknowledgements}

The authors would like to acknowledge funding from the Australian Grains Research and Development (GRDC), Curtin University, Commonwealth Scientific and Industrial Research Organization (CSIRO) and support from the Pawsey Supercomputing Centre. We thank Mathew Denton-Giles for his collaboration at the early stage of project conception.

\section{Consent for publication of data from individual person}

Not applicable.

\section{Authors' contributions}

WM, LGK, TEN and MCD designed the project, WWM performed the RNAseq experiment and wrote the first manuscript draft, WWM and RR conducted the GPCR validation experiment, WWM, FMM and MCD analysed the data. WWM and MCD wrote the manuscript. All authors read and approved the final manuscript.

\section{Funding}

This research was funded through a bilateral agreement between the Grains Research and Development Corporation of Australia and Curtin University, Perth, Australia, under grants CUR00023 and CUR00024. A Curtin University RTP scholarship and CSIRO Research Plus Top-up scholarship were awarded to WWM

\section{Availability of data and materials}

The raw data used in this study has been deposited to the sequence read archive under BioProject ID: PRJNA687280. The gene identifiers prefixed with 'sscle_' used throughout this manuscript are locus tags of S. sclerotiorum proteins that are available in the NCBI protein database.

\section{Ethics approval and consent to participate}

All the field experiment conducted in this study were in accordance with institutional and national guidelines set for the research stations/institutions. The seeds species involved in this study were provided by the Australian Grains Gene Bank (AGG; Horsham, Victoria) and do not include endangered species. Therefore, it does not require ethical approval.

\section{Consent for publication}

All the authors read and approved the final manuscript.

\section{Competing interests}

The authors declare that they have no competing interests.

\section{Author details}

'Centre for Crop and Disease Management, Curtin University, Bentley, WA 6102, Australia. ${ }^{2}$ Commonwealth Scientific and Industrial Research Organization, Agriculture and Food, Floreat, WA, Australia.

Received: 31 December 2020 Accepted: 27 April 2021

Published online: 08 May 2021

\section{References}

1. Boland GJ, Hall R. Index of plant hosts of Sclerotinia sclerotiorum. Can J Plant Pathol. 1994;16(2):93-108. https://doi.org/10.1080/07060669409500766.

2. Liang $X$, Rollins JA. Mechanisms of broad host range necrotrophic pathogenesis in Sclerotinia sclerotiorum. Phytopathology. 2018;108:1128-40.

3. Kukreja S, Salaria N, Thakur K, Goutam U. Fungal disease management in chickpea: current status and future prospects. In: Gehlot P, Singh J, editors. Fungi and their role in sustainable development: current perspectives. Singapore: Springer; 2018. p. 293-309. https://doi.org/10.1007/978-981-13-03 93-7_17.

4. Sclerotinia rot of chickpea. field crop diseases Victoria. https://extensionaus. com.au/FieldCropDiseasesVic/docs/identification-management-of-field-cropdiseases-in-victoria/chickpeas/sclerotinia-rot-of-chickpea/. Accessed 27 Jan 2021.

5. Fuhlbohm MJ, Tatnell JR, Ryley MJ. First report of stem rot and wilt of chickpea caused by Sclerotinia minor in Queensland, Australia. Australas Plant Pathol. 2003;2:323-4.

6. Kabbage M, Yarden O, Dickman MB. Pathogenic attributes of Sclerotinia sclerotiorum: switching from a biotrophic to necrotrophic lifestyle. Plant Sci. 2015;233:53-60. https://doi.org/10.1016/j.plantsci.2014.12.018.

7. Seifbarghi S, Borhan MH, Wei Y, Coutu C, Robinson SJ, Hegedus DD. Changes in the Sclerotinia sclerotiorum transcriptome during infection of Brassica napus. BMC Genomics. 2017;18(1):266. https://doi.org/10.1186/s12 864-017-3642-5.

8. Tang L, Yang G, Ma M, Liu X, Li B, Xie J, et al. An effector of a necrotrophic fungal pathogen targets the calcium-sensing receptor in chloroplasts to inhibit host resistance. Mol Plant Pathol. 2020;21(5):686-701. https://doi. org/10.1111/mpp.12922.

9. Zhu W, Wei W, Fu Y, Cheng J, Xie J, Li G, et al. A secretory protein of necrotrophic fungus sclerotinia sclerotiorum that suppresses host resistance. PLoS One. 2013:8.

10. Kabbage M, Williams B, Dickman MB. Cell death control: the interplay of apoptosis and autophagy in the pathogenicity of Sclerotinia sclerotiorum. PLoS Pathog. 2013;9(4):e1003287. https://doi.org/10.1371/journal.ppat.10032 87.

11. Li M, Liang X, Rollins JA. Sclerotinia sclerotiorum $Y$-Glutamyl Transpeptidase (Ss-Ggt1) is required for regulating glutathione accumulation and development of sclerotia and compound appressoria. Mol Plant-Microbe Interact. 2011;25:412-20.

12. Xiao X, Xie J, Cheng J, Li G, Yi X, Jiang D, et al. Novel secretory protein sscaf1 of the plant-pathogenic fungus Sclerotinia sclerotiorum is required for host penetration and normal sclerotial development. Mol Plant-Microbe Interact. 2013;27:40-55.

13. Derbyshire M, Denton-Giles M, Hegedus D, Seifbarghy S, Rollins J, van Kan J, et al. The complete genome sequence of the phytopathogenic fungus Sclerotinia sclerotiorum reveals insights into the genome architecture of broad host range pathogens. Genome Biol Evol. 2017;9(3):593-618. https:// doi.org/10.1093/gbe/evx030.

14. Bolton MD, Thomma BPHJ, Nelson BD. Sclerotinia sclerotiorum (lib.) de Bary: biology and molecular traits of a cosmopolitan pathogen. Mol Plant Pathol. 2006:7(1):1-16. https://doi.org/10.1111/j.1364-3703.2005.00316.x.

15. Amselem J, Cuomo CA, van Kan JAL, Viaud M, Benito EP, Couloux A, et al. Genomic analysis of the necrotrophic fungal pathogens Sclerotinia sclerotiorum and Botrytis cinerea. PLoS Genet. 2011;7(8):e1002230. https://doi. org/10.1371/journal.pgen.1002230.

16. Casadevall A, Pirofski L. Host-pathogen interactions: redefining the basic concepts of virulence and pathogenicity. Infect Immun. 1999;67(8):3703-13. https://doi.org/10.1128/IAl.67.8.3703-3713.1999.

17. Kubicek CP, Starr TL, Glass NL. Plant cell wall-degrading enzymes and their secretion in plant-pathogenic fungi. Annu Rev Phytopathol. 2014;52(1):42751. https://doi.org/10.1146/annurev-phyto-102313-045831.

18. Yajima W, Liang Y, Kav NNV. Gene disruption of an arabinofuranosidase/ beta-xylosidase precursor decreases Sclerotinia sclerotiorum virulence on 
canola tissue. Mol Plant-Microbe Interact. 2009;22(7):783-9. https://doi.org/1 0.1094/MPMI-22-7-0783.

19. Lyu X, Shen C, Fu Y, Xie J, Jiang D, Li G, et al. A small secreted virulencerelated protein is essential for the necrotrophic interactions of Sclerotinia sclerotiorum with its host plants. PLoS Pathog. 2016;12(2):e1005435. https:// doi.org/10.1371/journal.ppat.1005435.

20. Casadevall A. Determinants of virulence in the pathogenic fungi. Fungal Biol Rev. 2007;21 (4):130-2. https://doi.org/10.1016/j.fbr.2007.02.007.

21. Poussereau N, Creton S, Billon-Grand G, Rascle C, Fevre M. Regulation of acp1, encoding a non-aspartyl acid protease expressed during pathogenesis of Sclerotinia sclerotiorum. Microbiology. 2001;147(3):717-26. https://doi. org/10.1099/00221287-147-3-717.

22. Oliveira MB, de Andrade RV, Grossi-de-Sá MF, Petrofeza S. Analysis of genes that are differentially expressed during the Sclerotinia sclerotiorum-Phaseolus vulgaris interaction. Front Microbiol. 2015:6:1162.

23. Westrick NM, Ranjan A, Jain S, Grau CR, Smith DL, Kabbage M. Gene regulation of Sclerotinia sclerotiorum during infection of Glycine max: on the road to pathogenesis. BMC Genomics. 2019;20(1):157. https://doi.org/10.11 86/s12864-019-5517-4

24. Chittem K, Yajima WR, Goswami RS, del Río Mendoza LE. Transcriptome analysis of the plant pathogen Sclerotinia sclerotiorum interaction with resistant and susceptible canola (Brassica napus) lines. PLoS One. 2020;15(3): e0229844. https://doi.org/10.1371/journal.pone.0229844.

25. Segers G, Bradshaw N, Archer D, Blissett K, Oliver RP. Alcohol oxidase is a novel pathogenicity factor for Cladosporium fulvum, but aldehyde dehydrogenase is dispensable. Mol Plant-Microbe Interact. 2001;14:367-77.

26. Ohtaki S, Maeda H, Takahashi T, Yamagata Y, Hasegawa F, Gomi K, et al. Novel hydrophobic surface binding protein, HsbA, produced by Aspergillus oryzae. Appl Environ Microbiol. 2006;72(4):2407-13. https://doi.org/10.1128/A EM.72.4.2407-2413.2006.

27. Liu T, Chen G, Min H, Lin F. MoFLP1, encoding a novel fungal fasciclin-like protein, is involved in conidiation and pathogenicity in Magnaporthe oryzae. J Zhejiang Univ Sci B. 2009;10(6):434-44. https://doi.org/10.1631/jzus.B092 0017.

28. Stincone A, Prigione A, Cramer T, Wamelink MMC, Campbell K, Cheung E, et al. The return of metabolism: biochemistry and physiology of the pentose phosphate pathway. Biol Rev. 2015;90(3):927-63. https://doi.org/1 0.1111/brv.12140.

29. Stotz HU, Sawada Y, Shimada Y, Hirai MY, Sasaki E, Krischke M, et al. Role of camalexin, indole glucosinolates, and side chain modification of glucosinolate-derived isothiocyanates in defense of Arabidopsis against Sclerotinia sclerotiorum. Plant J. 2011;67(1):81-93. https://doi.org/10.1111/j.13 65-313X.2011.04578.x.

30. Sambasivam P, Mehmood Y, Bar I, Davidson J, Hobson K, Moore K, et al. Evidence of recent increased pathogenicity within the Australian Ascochyta rabiei population. bioRxiv. 2020; 2020.06.28.175653.

31. Ding Y, Mei J, Chai Y, Yang W, Mao Y, Yan B, et al. Sclerotinia sclerotiorum utilises host-derived copper for ROS detoxification and infection. PLoS Pathog. 2020;16(10):e1008919. https://doi.org/10.1371/ journal.ppat.1008919.

32. Heredia A, Dominguez E. The plant cuticle: a complex lipid barrier between the plant and the environment. An overview. In: Dishovsky C, Pivovarov A, editors. Counteraction to chemical and biological terrorism in east european countries. Dordrecht: Springer Netherlands; 2009. p. 109-16.

33. Reis $\mathrm{H}$, Pfiffi $\mathrm{S}$, Hahn M. Molecular and functional characterisation of a secreted lipase from Botrytis cinerea. Mol Plant Pathol. 2005;6(3):257-67. https://doi.org/10.1111/j.1364-3703.2005.00280.x.

34. Lehtinen U. Plant cell wall degrading enzymes of Septoria nodorum. Physiol Mol Plant Pathol. 1993;43(2):121-34. https://doi.org/10.1006/ pmpp.1993.1045.

35. Alghisi $P$, Favaron F. Pectin-degrading enzymes and plant-parasite interactions. Eur J Plant Pathol. 1995;101(4):365-75. https://doi.org/10.1007/ BF01874850.

36. ten Have A, Mulder W, Visser J, van Kan JA. The endopolygalacturonase gene Bcpg1 is required for full virulence of Botrytis cinerea. Mol PlantMicrobe Interact. 1998;11(10):1009-16. https://doi.org/10.1094/MPMl.1 998.11.10.1009.

37. Bashi ZD, Rimmer SR, Khachatourians GG, Hegedus DD. Brassica napus polygalacturonase inhibitor proteins inhibit Sclerotinia sclerotiorum polygalacturonase enzymatic and necrotising activities and delay symptoms in transgenic plants. Can J Microbiol. 2012;59:79-86.
38. Kars I, Krooshof GH, Wagemakers L, Joosten R, Benen JAE, Kan JALV. Necrotising activity of five Botrytis cinerea endopolygalacturonases produced in Pichia pastoris. Plant J. 2005;43(2):213-25. https://doi.org/10.1111/j.13 65-313X.2005.02436.x.

39. Wilson RA, Jenkinson JM, Gibson RP, Littlechild JA, Wang Z-Y, Talbot NJ. Tps1 regulates the pentose phosphate pathway, nitrogen metabolism and fungal virulence. EMBO J. 2007;26(15):3673-85. https://doi.org/10.1038/sj. emboj.7601795.

40. Franceschetti M, Maqbool A, Jiménez-Dalmaroni MJ, Pennington HG, Kamoun S, Banfield MJ. Effectors of filamentous plant pathogens: commonalities amid diversity. Microbiol Mol Biol Rev. 2017;81(2). https://doi. org/10.1128/MMBR.00066-16

41. Rementeria A, López-Molina N, Ludwig A, Vivanco AB, Bikandi J, Pontón J, et al. Genes and molecules involved in Aspergillus fumigatus virulence. Rev Iberoam Micol. 2005;22(1):1-23. https://doi.org/10.1016/S1130-14 06(05)70001-2.

42. Liang Y, Xiong W, Steinkellner S, Feng J. Deficiency of the melanin biosynthesis genes SCD1 and THR1 affects sclerotial development and vegetative growth, but not pathogenicity, in Sclerotinia sclerotiorum. Mol Plant Pathol. 2018;19(6):1444-53. https://doi.org/10.1111/mpp.12627.

43. Gullner G, Komives T, Király L, Schröder P. Glutathione S-transferase enzymes in plant-pathogen interactions. Front Plant Sci. 2018;9. https://doi.org/10.33 89/fpls.2018.01836

44. Sexton AC, Minic Z, Cozijnsen AJ, Pedras MSC, Howlett BJ. Cloning, purification and characterisation of brassinin glucosyltransferase, a phytoalexin-detoxifying enzyme from the plant pathogen Sclerotinia sclerotiorum. Fungal Genet Biol. 2009;46(2):201-9. https://doi.org/10.1016/j. fgb.2008.10.014.

45. Calmes B, Morel-Rouhier M, Bataillé-Simoneau N, Gelhaye E, Guillemette T, Simoneau P. Characterization of glutathione transferases involved in the pathogenicity of Alternaria brassicicola. BMC Microbiol. 2015;15(1):123. https://doi.org/10.1186/s12866-015-0462-0.

46. Harwood CS, Parales RE. The $\beta$-ketoadipate pathway and the biology of selfidentity. Annu Rev Microbiol. 1996;50(1):553-90. https://doi.org/10.1146/a nnurev.micro.50.1.553.

47. Faber BW, van Gorcom RFM, Duine JA. Purification and characterisation of benzoate-Para-hydroxylase, a cytochrome P450 (CYP53A1), from Aspergillus niger. Arch Biochem Biophys. 2001;394(2):245-54. https://doi.org/10.1006/a bbi.2001.2534

48. Rollins JA. The Sclerotinia sclerotiorum pacl gene is required for sclerotial development and virulence. Mol Plant-Microbe Interact. 2003:16:785-95.

49. Fan H, Yu G, Liu Y, Zhang X, Liu J, Zhang Y, et al. An atypical forkheadcontaining transcription factor SsFKH1 is involved in sclerotial formation and is essential for pathogenicity in Sclerotinia sclerotiorum. Mol Plant Pathol. 2017;18(7):963-75. https://doi.org/10.1111/mpp.12453.

50. Duan Y, Ge C, Liu S, Wang J, Zhou M. A two-component histidine kinase Shk1 controls stress response, sclerotial formation and fungicide resistance in Sclerotinia sclerotiorum. Mol Plant Pathol. 2013;14(7):708-18. https://doi. org/10.1111/mpp.12041.

51. Guyon K, Balagué C, Roby D, Raffaele S. Secretome analysis reveals effector candidates associated with broad host range necrotrophy in the fungal plant pathogen Sclerotinia sclerotiorum. BMC Genomics. 2014; 15:1-19.

52. Dallal Bashi Z, Hegedus DD, Buchwaldt L, Rimmer SR, Borhan MH. Expression and regulation of Sclerotinia sclerotiorum necrosis and ethyleneinducing peptides (NEPs). Mol Plant Pathol. 2010;11(1):43-53. https://doi. org/10.1111/j.1364-3703.2009.00571.x

53. Schouten A, van Baarlen P, van Kan JAL. Phytotoxic Nep1-like proteins from the necrotrophic fungus Botrytis cinerea associate with membranes and the nucleus of plant cells. New Phytol. 2008;177(2):493-505. https://doi.org/1 $0.1111 / j .1469-8137.2007 .02274 . x$.

54. Kim KS, Min J-Y, Dickman MB. Oxalic acid is an elicitor of plant programmed cell death during Sclerotinia sclerotiorum disease development. Mol PlantMicrobe Interact. 2008;21:605-12.

55. Heard S, Brown NA, Hammond-Kosack K. An interspecies comparative analysis of the predicted secretomes of the necrotrophic plant pathogens Sclerotinia sclerotiorum and Botrytis cinerea. PLoS One. 2015;10(6):e0130534. https://doi.org/10.1371/journal.pone.0130534.

56. Li R, Rimmer R, Buchwaldt L, Sharpe AG, Séguin-Swartz G, Hegedus DD. Interaction of Sclerotinia sclerotiorum with Brassica napus: cloning and characterisation of endo- and exo-polygalacturonases expressed during 
saprophytic and parasitic modes. Fungal Genet Biol. 2004;41(8):754-65. https://doi.org/10.1016/j.fgb.2004.03.002.

57. Xu L, Xiang M, White D, Chen W. pH dependency of sclerotial development and pathogenicity revealed by using genetically defined oxalate-minus mutants of Sclerotinia sclerotiorum. Environ Microbiol. 2015;17(8):2896-909. https://doi.org/10.1111/1462-2920.12818.

58. Kim H, Chen C, Kabbage M, Dickman MB. Identification and characterisation of Sclerotinia sclerotiorum NADPH oxidases. Appl Environ Microbiol. 2011; 77(21):7721-9. https://doi.org/10.1128/AEM.05472-11.

59. Schaffer WM, Bronnikova TV. Peroxidase-ROS interactions. Nonlinear Dyn. 2012;68(3):413-30. https://doi.org/10.1007/s11071-011-0314-X.

60. Yarden O, Veluchamy S, Dickman MB, Kabbage M. Sclerotinia sclerotiorum catalase SCAT1 affects oxidative stress tolerance, regulates ergosterol levels and controls pathogenic development. Physiol Mol Plant Pathol. 2014;85: 34-41. https://doi.org/10.1016/j.pmpp.2013.12.001.

61. Mwape WW, Khentry Y, Newman TE, Denton-Giles M, Derbyshire MC, Kefei C, et al. Identification of sources of Sclerotinia sclerotiorum resistance in a collection of wild Cicer germplasm. Plant Dis. 2021. https://doi.org/10.1094/ PDIS-02-21-0367-RE.

62. Denton-Giles M, Derbyshire MC, Khentry Y, Buchwaldt L, Kamphuis LG Partial stem resistance in Brassica napus to highly aggressive and genetically diverse Sclerotinia sclerotiorum isolates from Australia. Can J Plant Pathol. 2018;40(4):551-61. https://doi.org/10.1080/07060661.2018.1516699.

63. Bolger AM, Lohse M, Usadel B. Trimmomatic: a flexible trimmer for Illumina sequence data. Bioinformatics. 2014;30(15):2114-20. https://doi.org/10.1093/ bioinformatics/btu170.

64. Varshney RK, Song C, Saxena RK, Azam S, Yu S, Sharpe AG, et al. Draft genome sequence of chickpea (Cicer arietinum ) provides a resource for trait improvement. Nat Biotechnol. 2013;31(3):240-6. https://doi.org/10.1038/ nbt.2491.

65. Mwape WW, Khentry Y, Newman TE, Denton-Giles M, Derbyshire M, Chen K, Berger J, Kamphuis L. Identification of sources of Sclerotinia sclerotiorum resistance in a collection of wild Cicer germplasm. Plant Dis. 2021. https:// doi.org/10.1094/PDIS-02-21-0367-RE.

66. Li H, Handsaker B, Wysoker A, Fennell T, Ruan J, Homer N, et al. The sequence alignment/map format and SAMtools. Bioinform Oxf Engl. 2009; 25(16):2078-9. https://doi.org/10.1093/bioinformatics/btp352.

67. Anders S, Pyl PT, Huber W. HTSeq - a Python framework to work with highthroughput sequencing data. Bioinformatics. 2015;31(2):166-9. https://doi. org/10.1093/bioinformatics/btu638.

68. Robinson MD, McCarthy DJ, Smyth GK. edgeR: a bioconductor package for differential expression analysis of digital gene expression data. Bioinform Oxf Engl. 2010;26(1):139-40. https://doi.org/10.1093/bioinformatics/btp616.

69. Ritchie ME, Phipson B, Wu D, Hu Y, Law CW, Shi W, et al. Limma powers differential expression analyses for RNA-sequencing and microarray studies. Nucleic Acids Res. 2015;43(7):e47. https://doi.org/10.1093/nar/gkv007.

70. Lun ATL, Chen Y, Smyth GK. It's DE-licious: a recipe for differential expression analyses of RNA-seq experiments using quasi-likelihood methods in edgeR. Methods Mol Biol. 2016;1418:391-416. https://doi.org/10.1007/ 978-1-4939-3578-9 19.

71. Alexa A, Rahnenführer J, Lengauer T. Improved scoring of functional groups from gene expression data by decorrelating $\mathrm{GO}$ graph structure. Bioinform Oxf Engl. 2006;22(13):1600-7. https://doi.org/10.1093/bioinformatics/btl140

72. Zhang H, Yohe T, Huang L, Entwistle S, Wu P, Yang Z, et al. dbCAN2: a meta server for automated carbohydrate-active enzyme annotation. Nucleic Acids Res. 2018:46:W95-101.

73. Livak KJ, Schmittgen TD. Analysis of relative gene expression data using real-time quantitative $P C R$ and the $2-\Delta \Delta C T$ method. Methods. 2001;25(4): 402-8. https://doi.org/10.1006/meth.2001.1262

\section{Publisher's Note}

Springer Nature remains neutral with regard to jurisdictional claims in published maps and institutional affiliations.

Ready to submit your research? Choose BMC and benefit from:

- fast, convenient online submission

- thorough peer review by experienced researchers in your field

- rapid publication on acceptance

- support for research data, including large and complex data types

- gold Open Access which fosters wider collaboration and increased citations

- maximum visibility for your research: over $100 \mathrm{M}$ website views per year

At $\mathrm{BMC}$, research is always in progress.

Learn more biomedcentral.com/submissions 